\title{
Expressão em Escherichia coli da Proteína Capsidial do Watermelon mosaic virus e Produção de Anti-Soro*
}

\author{
Manuela R. Barbieri, Murilo G. de Carvalho, Eunize M. Zambolim \& F. Murilo Zerbini** \\ Departamento de Fitopatologia/BIOAGRO, Universidade Federal de Viçosa, Viçosa, MG, CEP 36570-000, e-mail: zerbini@ufv.br
}

(Aceito para publicação em 07/11/2003)

Autor para correspondência: F. Murilo Zerbini

BARBIERI, M.R., CARVALHO, M.G., ZAMBOLIM, E.M. \& ZERBINI, F.M. Expressão em Escherichia coli da proteína capsidial do Watermelon mosaic virus e produção de anti-soro. Fitopatologia Brasileira 29:215-219. 2004.

\section{RESUMO}

Um anti-soro policlonal específico para Watermelon mosaic virus (WMV) foi produzido por meio da imunização de coelhos com proteína capsidial purificada, expressa in vitro em células de Escherichia coli. O gene $c p$ foi amplificado via RT-PCR utilizando oligonucleotídeos específicos, a partir de RNA viral extraído de preparações virais concentradas. $\mathrm{O}$ fragmento amplificado foi clonado em pBLUESCRIPT KS+ e completamente seqüenciado para confirmação de sua identidade e integridade. Em seguida, o fragmento foi subclonado no vetor de expressão pRSET-A. Plasmídeos recombinantes foram utilizados para a expressão da proteína capsidial em E. coli BL21::DE3. A proteína foi purificada por meio de cromatografia de afinidade em coluna de $\mathrm{Ni}^{+}$-NTA, a partir de proteínas totais extraídas de E. coli. Uma vez purificada, a proteína foi quantificada e utilizada para imunização dos coelhos. O antisoro foi testado quanto a sua especificidade e sensibilidade em testes de Western blot, DAS-ELISA, imunodifusão e ELISA indireto. Todos os testes demonstraram que o anti-soro produzido a partir da expressão in vitro da proteína capsidial é altamente específico para a detecção do WMV em extratos foliares, não tendo sido observada nenhuma reação heteróloga interespecífica.

Palavras-chave adicionais: Cucurbitáceas, ELISA, imunodifusão, Western blot.

\begin{abstract}
Expression in Escherichia coli of the capsid protein of Watermelon mosaic virus and production of specific antiserum

A Watermelon mosaic virus (WMV)-specific, polyclonal antiserum was raised in rabbits by immunization with purified capsid protein expressed and purified from Escherichia coli cells. The $c p$ gene was RT-PCR-amplified using specific oligonucleotides, and viral RNA extracted from concentrated particles as a template. The amplified fragment was cloned in pBLUESCRIPT KS+ and fully sequenced in order to confirm its identity and integrity. The fragment was subsequently subcloned into the pRSET-A expression vector.

Recombinant plasmids were used to induce the expression of the capsid protein in E. coli BL21::DE3. The protein was purified by affinity chromatography using a $\mathrm{Ni}^{+}-\mathrm{NTA}$ resin, from $E$. coli total protein extract. The purified protein was quantified and used for the immunization of rabbits. The antiserum was tested for its sensitivity and specificity in Western blot, DAS-ELISA, immunodiffusion and indirect ELISA assays. All tests indicated that the antiserum raised from in vitro-expressed capsid protein is highly specific for the detection of WMV in plant extracts, with no interspecific, heterologous reactions being observed.
\end{abstract}

O cultivo de cucurbitáceas é uma atividade de caráter intensivo, concentrada nos cinturões verdes localizados ao redor das grandes cidades. As principais espécies cultivadas são a abóbora [Cucurbita moschata (Duch.) Duch. ex Poir], abobrinha (Cucurbita pepo L.), melancia [Citrullus lanatus (Thunb.) Matsum. \& Nakai], melão (Cucumis melo L.) e pepino (Cucumis sativus L.). As doenças causadas por vírus são um dos mais graves problemas fitossanitários dessas culturas. As características de incidência e severidade variam consideravelmente em função da espécie viral e suas estirpes, espécie hospedeira, disponibilidade de fontes de inóculo, população e atividade de insetos vetores, e condições ambientais (Lima \& Vieira, 1992). No Brasil, o vírus da mancha anelar do mamoeiro, estirpe melancia (Papaya ringspot virus - watermelon, PRSV-

\footnotetext{
*Parte da dissertação de Mestrado do primeiro autor. Universidade Federal de Viçosa. (2003)

***Bolsista do CNPq
}

W), o vírus do mosaico da melancia (Watermelon mosaic virus, WMV) e o vírus do mosaico amarelo da abobrinha (Zucchini yellow mosaic virus, ZYMV), todos da família Potyviridae, gênero Potyvirus, são atualmente os vírus de maior incidência (Richards, 1999; Oliveira et al., 2000; Yuki et al., 2000; Moura et al., 2001).

O WMV foi relatado pela primeira vez no Brasil por Sá et al. (1988). É um potyvírus típico, com partículas alongadas, flexuosas, com 690-760 nm de comprimento por 11-16 nm de diâmetro, e genoma composto por uma única molécula de RNA de fita simples, polaridade positiva, com aproximadamente 10.000 nucleotídeos, envolta por uma proteína capsidial com peso molecular de aproximadamente $34 \mathrm{kDa}$. O WMV causa mosqueado, mosaico e deformação foliar e dos frutos, sendo os sintomas passíveis de serem confundidos com aqueles induzidos por outros vírus que infetam cucurbitáceas (Oliveira et al., 2000). Possui ampla gama de hospedeiros, infetando 178 
espécies de plantas em 27 famílias. O vírus é transmitido de maneira não-circulativa por mais de 38 espécies de afídeos, porém não é transmitido pela semente (Shukla et al., 1994).

Além das infecções causadas pelos vírus isoladamente, infecções mistas em cucurbitáceas são observadas com grande frequiência em condições naturais, devido aos vírus serem transmitidos pelos mesmos insetos vetores, de maneira nãocirculativa. Esse fato torna virtualmente impossível a diagnose baseada em sintomas, devido a mudanças no quadro sintomatológico típico para cada vírus. A correta identificação do(s) vírus presente(s) em amostras provenientes do campo é essencial para que medidas de controle adequadas possam ser recomendadas. A disponibilidade de um método sensível, específico e eficiente de detecção e identificação viral é fundamental.

Tradicionalmente, a sorologia tem sido o método mais utilizado para a detecção e diagnose de vírus de plantas, incluindo os potyvírus (Shukla et al., 1994; Hull, 2002). No caso específico dos três potyvírus que infetam cucurbitáceas (PRSV-W, WMV e ZYMV), o emprego de testes sorológicos na diagnose exige anti-soros de alta qualidade, produzidos a partir de preparações purificadas nas quais as partículas virais estejam as mais íntegras possíveis. Caso contrário, a porção amino-terminal da proteína capsidial será removida e os epitopos espécie-específicos localizados nessa região serão perdidos, gerando um anti-soro incapaz de diferenciar espécies de potyvírus, com a observação de reações cruzadas (Shukla et al., 1994). A produção de anti-soros é normalmente realizada via injeção de partículas virais purificadas na corrente sangüínea de coelhos (Hull, 2002). Entretanto, a purificação de um vírus será sempre um processo trabalhoso, e que comumente produz preparações com pureza e concentração insatisfatórias. É comum que anti-soros produzidos a partir de preparações purificadas distintas possuam título e especificidades distintos.

Atualmente, com a utilização de técnicas de biologia molecular, tem-se tornado comum a clonagem do gene da proteína capsidial $(c p)$ de vírus em vetores que permitem sua expressão em Escherichia coli (Colinet et al., 1994). A clonagem do gene $c p$ permite que quantidades virtualmente ilimitadas da proteína sejam produzidas, pois os clones podem ser armazenados por tempo indeterminado a $-80^{\circ} \mathrm{C}$, bastando o cultivo de uma cultura bacteriana para obtenção da proteína. Uma vez que para a grande maioria dos vírus de plantas a proteína capsidial é a única proteína com propriedades imunogênicas, um anti-soro produzido a partir da proteína livre apresentará as mesmas propriedades daquele produzido a partir de partículas virais purificadas. Além disso, como o protocolo de purificação da proteína a partir de E. coli é extremamente simples, preparações distintas possuirão as mesmas propriedades, levando à produção de anti-soros que também apresentarão as mesmas propriedades. Com base nessas considerações, este trabalho teve como objetivos a produção de anti-soro específico para o WMV a partir de proteína capsidial expressa in vitro em $E$. coli, e a caracterização do anti-soro.

O isolado de WMV foi fornecido pelo Prof. M.A. Pavan
(UNESP, Botucatu, SP). O isolado foi caracterizado molecularmente por Richards (1999), e foi mantido em plantas de C. pepo 'Caserta' em casa-de-vegetação, por meio de inoculações mecânicas sucessivas via extrato vegetal tamponado em fosfato de potássio $0,02 \mathrm{M}$, pH 7,2, contendo sulfito de sódio a $0,01 \%$. A preservação in vitro foi realizada mediante o corte e dessecamento das primeiras folhas infetadas pelo vírus e armazenamento a $-20^{\circ} \mathrm{C}$.

Folhas de $C$. pepo 'Caserta' com plenos sintomas da virose foram coletadas e utilizadas para a obtenção de uma preparação viral concentrada conforme descrito por Lane (1992). O RNA viral foi extraído a partir da preparação viral concentrada, conforme descrito por Krause-Sakate et al. (2001) e utilizado como molde para a síntese de uma fita de DNA complementar (cDNA) via transcrição reversa, utilizando-se o kit "SuperScript Preamplification System for First Strand cDNA Synthesis" (Invitrogen) e um oligonucleotídeo com uma cauda poli-T (poli-T: 5'G-A-C-T-G-G-A-T-C-C-T(14)3'). Para a amplificação do gene $c p$ via reação em cadeia da polimerase (PCR) foram utilizados oligonucleotídeos específicos para a proteína capsidial (CP) do WMV (5'-G-A-T-C-G-G-A-T-C-CT-C-A-G-G-A-A-A-A-G-A-A-A-C-A-G-T-T-3', sítio para BamH I sublinhado, e 5'-C-A-T-G-G-A-A-T-T-C-T-C-T-T-TA-C-T-G-C-G-G-T-G-G-A-C-C-3', sítio para EcoR I sublinhado), cujas sequiências foram determinadas com base nas seqüências de outros isolados desse vírus, previamente publicadas (Shukla et al., 1994). As condições de RT-PCR foram as mesmas descritas por Krause-Sakate et al. (2001).

O produto da reação de RT-PCR e o plasmídeo vetor pBLUESCRIPT KS+ (pKS+) foram digeridos com as enzimas $B a m \mathrm{H}$ I e EcoR I e purificados a partir de gel de agarose utilizando-se uma matriz sólida (Sephaglass Bandprep, Amersham Biosciences), de acordo com as instruções do fabricante. A ligação entre o fragmento viral e o DNA plasmidial, transformação de E. coli DH5a e seleção de clones recombinantes foram realizados de acordo com técnicas padrão (Sambrook et al., 1989). O fragmento viral clonado foi completamente seqüenciado utilizando-se o kit "Termocycle Sequencing Dye Terminator" (Perkin-Elmer) e um sequienciador automático ABI 310 (Applied Biosystems).

Uma vez confirmada a identidade do fragmento clonado, este foi retirado do vetor $\mathrm{pKS}+$ por meio de digestão com $E c o \mathrm{R}$ I e BamH I, e ligado ao vetor de expressão pRSET-A, previamente digerido com as mesmas enzimas. A ligação, transformação de E. coli e identificação dos clones recombinantes foram realizados de acordo com técnicas padrão (Sambrook et al., 1989).

Para a expressão in vitro, o vetor pRSET-A contendo o inserto viral foi transferido para a estirpe BL21::DE3 de E. coli, de acordo com técnicas padrão (Sambrook et al., 1989). Após incubação em meio sólido, uma colônia foi selecionada e utilizada para a inoculação de $200 \mathrm{ml}$ de meio LB líquido com ampicilina em um erlenmeyer de 1 litro. Essa cultura foi incubada a 37 ?C até $\mathrm{OD}_{600}$ de aproximadamente 0,5. Nesse ponto a expressão da CP foi induzida por meio da adição de IPTG à concentração final de $10 \mathrm{mM}$. Exatamente $4 \mathrm{~h}$ após a 
indução, as células foram coletadas por centrifugação $(5.000 \mathrm{~g} /$ $10 \mathrm{~min})$. O pellet foi armazenado a -80 ?C.

Um extrato de proteínas totais de E. coli foi obtido conforme descrito por Noueiry et al. (1994). A purificação da CP a partir desse extrato foi realizada por cromatografia de afinidade em colunas de Ni-NTA (Qiagen), conforme instruções do fabricante. Inicialmente, a expressão da $\mathrm{CP}$ foi avaliada a partir do extrato de proteínas totais, por meio de eletroforese em gel de poliacrilamida contendo dodecil sulfato de sódio (SDS-PAGE). Após a purificação na coluna de Ni-NTA, a quantificação foi realizada pelo método de Bradford, utilizandose o kit "Dc Protein Assay" (Bio-Rad), de acordo com as instruções do fabricante.

As proteínas purificadas foram injetadas em dois coelhos brancos, da raça Nova Zelândia, com aproximadamente 30 dias de idade. Após coleta do sangue para obtenção do soro normal (pré-imune), foram realizadas cinco injeções intramusculares na coxa, a intervalos semanais, com $0,5 \mathrm{mg}$ de proteína por injeção em cada coelho. Duas semanas após a última injeção, foi retirada amostra de sangue para avaliação inicial do antisoro. Duas coletas adicionais foram realizadas, a intervalos quinzenais, após a coleta inicial.

O título do anti-soro foi determinado por meio de ELISA indireto (Clark et al., 1986), utilizando diluições do anti-soro a 1:50, 1:250, 1:500, 1:1.000, 1:2.000, 1:4.000, 1:8.000, 1:16.000, $1: 32.000$ e 1:64.000. A especificidade do anti-soro foi determinada em testes de Western blot, imunodifusão (Hampton et al., 1990), DAS-ELISA (Clark et al., 1986) e ELISA indireto, ao testar a reação com amostras de plantas sadias e infetadas pelo PRSV-W, WMV, ZYMV, vírus do mosaico da abóbora (Squash mosaic virus, SqMV) família Comoviridae, gênero Comovirus e vírus do mosaico da alface (Lettuce mosaic virus, LMV) família Potyviridae, gênero Potyvirus. Nos testes de imunodifusão e DAS-ELISA foi utilizado, além do anti-soro produzido a partir da $\mathrm{CP}$ expressa in vitro (AS-CP), um antisoro produzido a partir de partículas purificadas de WMV (AS$\mathrm{VP})$.

A amplificação do gene $c p$ do WMV via RT-PCR foi comprovada por meio de eletroforese em gel de agarose $(0,9 \%$ $\mathrm{p} / \mathrm{v}$ ), observando-se a presença do fragmento com o tamanho esperado (aproximadamente 800 pares de bases). $\mathrm{O}$ fragmento foi clonado em pKS+ e seqüenciado completamente, confirmando-se sua identidade e integridade (dados não apresentados).

A estirpe BL21::DE3 de E. coli foi transformada com o vetor pRSET-A contendo o inserto viral, e a expressão da proteína capsidial foi induzida em uma cultura de $200 \mathrm{ml}$ por meio da adição de IPTG. Após extração e purificação da $\mathrm{CP}$, a expressão foi confirmada por meio de SDS-PAGE, observandose a presença de uma banda cujo peso molecular correspondeu a aproximadamente $34 \mathrm{kDa}$, valor esperado para a CP do WMV (dados não apresentados). Foram realizadas três induções de culturas de E. coli a fim de obter a quantidade de proteína necessária para a imunização de dois coelhos.

Em ELISA indireto, o anti-soro obtido reagiu com extratos foliares de plantas infetadas pelo WMV até a diluição máxima testada (1:64.000) (dados não apresentados). A melhor reação foi obtida a uma diluição de 1:32.000, o que demonstra o ótimo título do anti-soro. O anti-soro foi testado para detecção específica do WMV em Western blot (Figura 1), DAS-ELISA (Figura 2), imunodifusão e ELISA indireto (dados não apresentados). Além do extrato de planta infetada pelo WMV, os testes incluíram extratos de plantas infetadas por três outras espécies de potyvírus (LMV, PRSV-W e ZYMV) o comovírus (SqMV), além da planta sadia. Em todos os testes o anti-soro reagiu apenas com o extrato de planta infetada com WMV, comprovando assim sua sensibilidade e especificidade.

Nos testes Western blot e ELISA indireto foi utilizado apenas o anti-soro produzido a partir da proteína expressa in vitro (AS-CP). O anti-soro apresentou-se altamente específico ao WMV e não reagiu com extrato de planta sadia ou com vírus heterólogos (LMV, PRSV-W, SqMV e ZYMV) (Figura 1 e dados não apresentados).

Nos testes de imunodifusão e DAS-ELISA foram utilizados ambos os anti-soros (AS-CP e AS-VP). O AS-CP foi específico para o WMV em ambos os testes, e novamente apresentou reação mais intensa com a proteína purificada em comparação ao extrato foliar infetado. Já o AS-VP apresentou reação cruzada com o ZYMV e, embora tenha apresentado reação positiva com o extrato de planta infetada pelo WMV, não reagiu com a $\mathrm{CP}$ purificada (Figura 2).

Os resultados dos diferentes testes sorológicos realizados indicaram claramente que o anti-soro produzido a partir da proteína expressa in vitro (AS-CP) é altamente específico e eficiente na deteç̧ão de WMV, pois apresentou forte reação homóloga diante da CP purificada e do extrato de planta infetada por WMV, e não reagiu com o extrato de planta sadia ou com

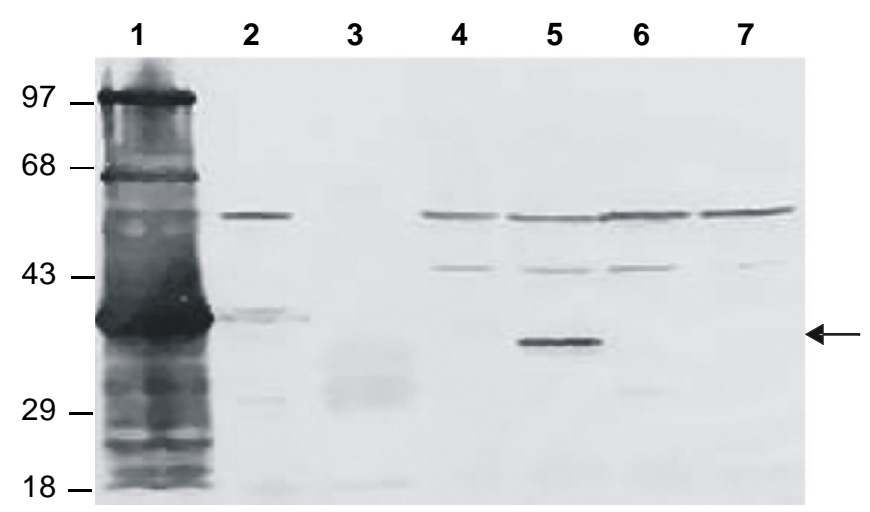

FIG. 1 - Western blot utilizando o anti-soro produzido a partir da proteína capsidial do Watermelon mosaic virus (WMV) expressa e purificada a partir de células de Escherichia coli. 1. Proteína capsidial do WMV purificada a partir de células de E. coli; 2. Proteína total extraída a partir de planta sadia; 3. Preparação concentrada de Papaya ringspot virus (PRSV-W); 4, 5, 6, 7. Proteína total extraída a partir de plantas infetadas por PRSV-W, WMV, Zucchini yellow nosaic virus (ZYMV) e Squash mosaic virus (SqMV), respectivamente. Os números à esquerda indicam a posição dos padrões de massa molecular, em kDa. A seta à direita indica a banda correspondente à proteína capsidial do WMV. 


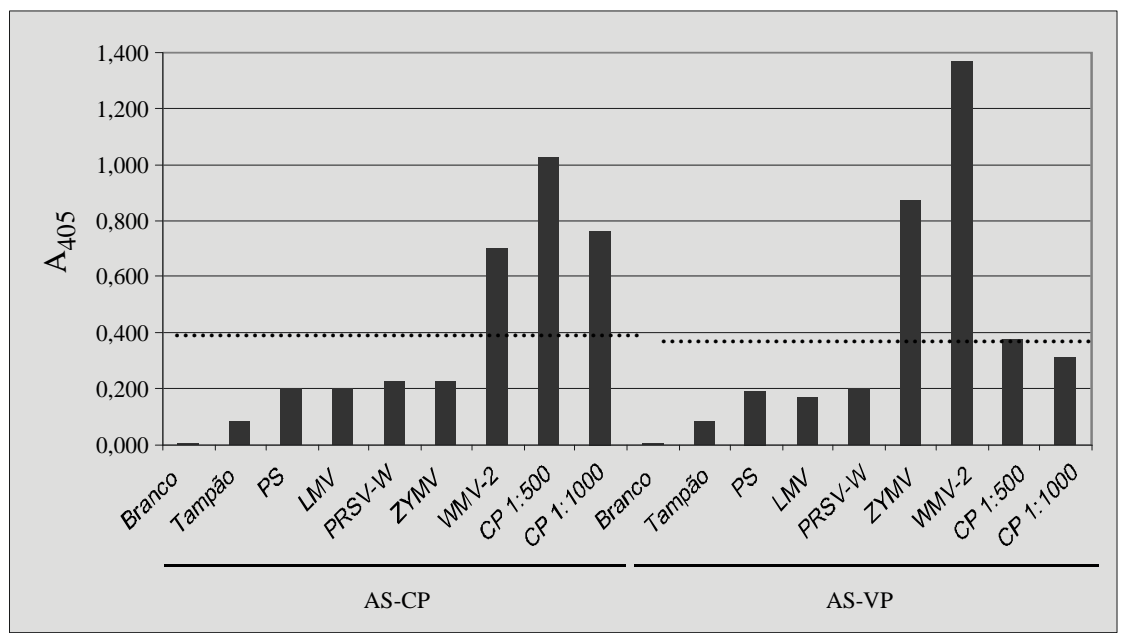

FIG. 2 - Representação gráfica dos resultados de DAS-ELISA utilizando anti-soro produzido a partir da proteína capsidial expressa e purificada de células de Escherichia coli (AS-CP) e antisoro produzido a partir de Watermelon mosaic virus (WMV) purificado (AS-VP), com o conjugado diluído 1:1.000 e o IgG na concentração de $1 \mu \mathrm{g} / \mathrm{ml}$. As linhas horizontais pontilhadas representam o limiar da reação positiva do anti-soro, correspondendo a duas vezes o valor de absorbância observado nas reações com o extrato de planta sadia. Tampão, PBS; PS, Extrato de planta sadia; LMV, PRSV-W, ZYMV, WMV, Extratos de plantas infetadas por LMV, PRSV-W, ZYMV, WMV, respectivamente; CP 1:500, CP 1:1000, Proteína capsidial do WMV purificada de E. coli, diluída 1:500 e 1:1000, respectivamente.

outras espécies de potyvírus que infetam cucurbitáceas. Já o anti-soro produzido a partir da injeção de partículas virais purificadas (AS-VP) não se mostrou específico para o WMV, pois ocorreu reação sorológica cruzada com o ZYMV. Em estudo comparando o relacionamento sorológico entre PRSVW, WMV e ZYMV em ELISA indireto, Oliveira et al. (2000) concluíram que o WMV e o ZYMV têm pelo menos um determinante antigênico em comum, o que pode resultar em reação sorológica cruzada entre esses dois vírus. Esse fato explicaria a reação cruzada verificada no presente trabalho com o AS-VP. A ausência de reação cruzada entre o AS-CP e o ZYMV poderia ser explicada caso o epitopo em comum entre as CPs do WMV e ZYMV seja conformacional. Uma vez que a proteína expressa in vitro é purificada e injetada nos coelhos na forma desnaturada, esse epitopo teria sido perdido, evitando a reação cruzada com o ZYMV. Já no vírus purificado esse epitopo teria sido mantido.

Em processos usuais de purificação de potyvírus o vírion íntegro pode perder os aminoácidos das extremidades amínica e carboxílica, expostos para o meio externo e conseqüentemente mais suscetíveis à degradação (Shukla et al., 1994). Com a expressão in vitro da $\mathrm{CP}$, esses aminoácidos foram preservados e, com eles, foram mantidas as propriedades imunogênicas do vírus. Entretanto, a desnaturação poderia expor epitopos conservados presentes na região central da proteína, normalmente encobertos na partícula viral. A exposição desses epitopos poderia levar à produção de anticorpos que iriam reconhecer a $\mathrm{CP}$ de outros potyvírus. A ausência de reações heterólogas entre o AS-CP e outros potyvírus sugere que esses epitopos não foram ativos na indução de anticorpos. É possível que fossem epitopos conformacionais, perdidos com a desnaturação da proteína, ou que não fossem conservados entre as proteínas capsidiais do WMV e dos outros potyvírus testados.

Com bases nos resultados obtidos pode-se concluir que o anti-soro produzido a partir da expressão da $\mathrm{CP}$ em E. coli é altamente eficiente e específico na detecção do WMV. O uso deste anti-soro permitirá um imunodiagnóstico preciso do WMV, devido à ausência de reação com extrato de planta sadia e de reações sorológicas cruzadas com os demais potyvírus que infetam cucurbitáceas.

\section{REFERÊNCIAS BIBLIOGRÁFICAS}

CLARK, M.F., LISTER, R.M. \& BAR-JOSEPH, M. ELISA techniques. Methods in Enzymology 118:742-766. 1986.

COLINET, D., KUMMERT, J. \& LEPOIVRE, P. The complete nucleotide sequences of the coat protein cistron and the 3 ' non-coding region of a newly-identified potyvirus infecting sweetpotato, as compared to those of sweetpotato feathery mottle virus. Archives of Virology 139:327-336. 1994.

HAMPTON, R., BALL, E. \& DE BOER, S. (Eds.) Serological tests for detection and identification of viral and bacterial plant pathogens. St. Paul: APS Press. 1990.

HULL, R. Matthew's Plant Virology (4a ed.). Londres, Inglaterra: Academic Press. 2002.

KRAUSE-SAKATE, R., MELLO, R.N., ZAMBOLIM, E.M., PAVAN, M.A., CARVALHO, M.G., LE GALL, O. \& ZERBINI, F.M. Molecular characterization of two Brazilian isolates of Lettuce mosaic virus (LMV) with distinct biological properties. Fitopatologia Brasileira 26:153-157. 2001. 
Expressão em Escherichia coli da proteína capsidial do Watermelon...

LANE, L.C. A general method for detecting plant viruses. In: Maramorosch, K. (Ed.) Plant diseases of viral, viroid, mycoplasma and uncertain origin. New Delhi: Oxford \& IBH Publishing. 1992. pp. 3-17.

LIMA, J.A.A. \& VIEIRA, A.C. Distribuição do vírus do mosaico da abóbora em municípios cearenses e gama de hospedeiros de um isolado. Fitopatologia Brasileira 17:112-114. 1992.

MOURA, M.C.C.L., LIMA, J.A.A., OLIVEIRA, V.B. \& GONÇALVES, M.F.B. Identificação sorológica de espécies de vírus que infectam cucurbitáceas em áreas produtoras do Maranhão. Fitopatologia Brasileira 26:90-92. 2001.

NOUEIRY, A.O., LUCAS, W.J. \& GILBERTSON, R.L. Two proteins of a plant DNA virus coordinate nuclear and plasmodesmal transport. Cell 76:925-932. 1994.

OLIVEIRA, V.B., LIMA, J.A.A., VALE, C.C. \& PAIVA, W.O. Caracterização biológica e sorológica de isolados de potyvírus obtidos de cucurbitáceas no Nordeste brasileiro. Fitopatologia Brasileira 25:628-636. 2000.
RICHARDS, R.S. Identificação, Caracterização Biológica e Obtenção de Sondas de cDNA para Vírus de Cucurbitáceas no Estado de Minas Gerais. (Tese de Mestrado), Departamento de Fitopatologia, Universidade Federal de Viçosa, Viçosa-MG. 1999.

SÁ, P.B., MARINHO, V.L.A., OLIVEIRA, C.R.B. \& KITAJIMA, E.W. Caracterização parcial de um isolado do vírus do mosaico da melancia-2 (watermelon mosaic virus-2) procedente de Campinas, SP. Fitopatologia Brasileira 13:145. 1988. (Resumo)

SAMBROOK, J., FRITSCH, E.F. \& MANIATIS, T. Molecular Cloning - A Laboratory Manual (2a ed.). Cold Spring Harbor, NY: Cold Spring Harbor Laboratory Press. 1989.

SHUKLA, D.D., WARD, C.W. \& BRUNT, A.A. The Potyviridae. Wallingford, UK: CAB International. 1994.

YUKI, V.A., REZENDE, J.A.M., KITAJIMA, E.W., BARROSO, P.A.V., KUNIYUKI, H., GROPPO, G.A. \& PAVAN, M.A. Occurrence, distribution, and relative incidence of five viruses infecting cucurbits in the State of São Paulo, Brazil. Plant Disease 84:516-520. 2000. 